\title{
COMUNICACIÓN/COMUNICATION
}

Recibido: 30/06/2011---Revisado: 03/09/2011

Aceptado: 22/11/2011---Publicado: 15/03/2012

\section{HACIA UN NUEVO MARCO REGULATORIO Y DE GESTIÓN DE LA TELEVISIÓN PÚBLICA EN ESPAÑA: EL BIENIO DEL CAMBIO}

Nereida López-Vidales: Universidad de Valladolid. España nereida.lopez@hmca.uva.es

Ana Azurmendi-Adarraga: Universidad de Navarra. España aazur@unav.es

Miguel Ángel Ortiz-Sobrino ${ }^{\mathbf{1}}$ : Universidad Complutense de Madrid. España amortiz.@ccinf.ucm.es

\section{RESUMEN}

La Ley General de Comunicación Audiovisual (7/2010 de 31 de marzo) se erige como la normativa básica de coordinación, ordenación y regulación de la comunicación audiovisual de ámbito estatal en España. Esta ley, que entró en vigor el 1 de mayo de ese mismo año, señala al nuevo contexto derivado de la evolución tecnológica y la digitalización como generadores inmediatos de la necesidad de cambios importantes en materia de regulación del sector audiovisual. La norma no ha estado exenta de interpretaciones polémicas. Entre ellas, la relacionada con una posible redefinición del servicio público de las radio- televisiones públicas, las críticas al modelo de gestión y financiación propuesto para sanear las cuentas de estas entidades o la creación de un órgano vigilante cuyas decisiones pudieran despertar ciertas incompatibilidades en el futuro. El nuevo mapa político surgido tras las últimas elecciones Generales y Autonómicas en España, está propiciando importantes redefiniciones para el modelo de gestión de la televisión pública en España, en especial, por lo que se refiere a la televisión pública autonómica y local y, en menor medida, también la nacional.

PALABRAS CLAVE: Radio-televisión pública - Ley General de Comunicación Audiovisual - Servicio público - Industria audiovisual - Reforma audiovisual

\footnotetext{
${ }^{1}$ Autor correspondiente

Miguel Ángel Ortiz-Sobrino: Profesor de Periodismo en la Universidad Complutense de Madrid. Delegado de Medialabab/Inforadio y miembro de la Comisión de Calidad para el Grado de Periodismo en la Facultad de Ciencias de la Información de Madrid
}

Correo: amortiz.@ccinf.ucm.es 


\title{
TOWARDS A NEW REGULATORY FRAMEWORK AND PUBLIC TELEVISION MANAGEMENT IN SPAIN: CHANGE THE BIENNIUM
}

\begin{abstract}
The new General Law on Audiovisual Communication (7 / 2010 of March 31) stands as the basic rules of coordination, management and regulation of state-wide audiovisual media in Spain. The Act, that came into force on May 1, points to the new situation arising from technological developments and digitization as generating immediate need for major changes in regulation of the audiovisual sector. The standard has not been exempted of controversial interpretations. Among them, related to a possible redefinition of the public service of public broadcasting, criticism of the management and funding model proposed to clean up the accounts of these entities or the creation of a watchdog body whose decisions may awaken certain incompatibilities in the future. The new political map out of the last General elections and Regional governments of Spain, is driving important redefinitions management model for public television in Spain, especially in regard to regional and local public television and to a lesser extent also national.
\end{abstract}

KEY WORDS: Public broadcasting - Audiovisual Communication Act - Public service Audiovisual industry - Audiovisual reform

\section{INTRODUCCIÓN}

Las radiotelevisiones públicas españolas están afrontando en el momento actual importantes retos y profundos cambios impulsados por un desarrollo tecnológico sin precedentes y la evolución de un mercado cambiante cuyas reglas, más allá de la natural competencia, están aún por definir. En un panorama audiovisual como el presente, donde se adivina cercana la mutación de los medios de comunicación considerados tradicionales, no sólo en cuanto a sus líneas programáticas o audiencias, sino en su mismo funcionamiento como empresa -su gestión interna y su financiación, era precisa una reforma del marco jurídico encargado de interpretar las nuevas condiciones.

El ordenamiento anterior, principalmente la Ley 4/1980 de 10 de enero del Estatuto de Radio y Televisión, se mostraba rígido a la hora de cubrir bajo su paraguas legal los cambios de modelo de negocio a los que se ven abocados los medios en la era de la convergencia multimedia. La ley 7/2010 General de lo Audiovisual, de 31 de marzo, tiene como principio inspirador modernizar el pensamiento legal del ámbito audiovisual, aunque, de nuevo, la diferente naturaleza de los actores implicados, pone en entredicho las supuestas ventajas de una uniformidad normativa que quiere un 
comportamiento similar para grupos de comunicación cuyas condiciones de actuación presente y futura son muy distintas, al igual que sus derechos y obligaciones.

Son varios los actores implicados en este proceso de cambio y adaptación continua; además de la radio y el cine, los servicios a través de Internet, la comunicación móvil, la televisión de alta definición y también en movilidad, la publicidad... pero son las cadenas de televisión, públicas y privadas, de titularidad estatal con cobertura nacional y autonómica, los operadores de comunicaciones, los más directamente afectados por el nuevo marco legislativo que comienza a aplicarse desde el 1 de mayo de 2010, fecha de entrada en vigor de la Ley General de lo Audiovisual para España.

Este nuevo ordenamiento jurídico redefine cuestiones trascendentales como los principios, criterios y objetivos del servicio público que deben prestar los distintos agentes, refuerza y garantiza su independencia, implanta nuevos instrumentos legales para dotar a las radiotelevisiones públicas de estabilidad y transparencia financiera, así como de eficaces estructuras organizativas y de gestión.

Sin embargo, el paso más importante en esta transformación del marco legal se inicia con la reforma audiovisual del Gobierno que terminó con el status quo establecido por el Estatuto de Radio y Televisión, por la que el Ente Público RTVE pasaba a constituir la Corporación RTVE, sustanciada en la Ley 17/2006, de Reforma de los Medios de Comunicación de Titularidad Estatal (ley que se completa con la Ley 8/2009, de Financiación de la Corporación de Radio y Televisión Española), y de la que es clara continuación la Ley General de Comunicación Audiovisual.

Como consecuencia, y hasta ahora, al hilo de la reforma emprendida con la Ley 17/2006, de 5 de junio, de la Radio y la Televisión de Titularidad Estatal, se han promulgado la Ley 11/2007, de 11 de octubre, de la Corporació Catalana de Mitjans Audiovisuals, la Ley 18/2007, de 17 de diciembre, de la Radio y Televisión de Titularidad Autonómica gestionada por la Agencia Pública Empresarial de la Radio y la Televisión de Andalucía (RTVA), y la LEY 3/2008, de 16 de junio, reguladora de la Empresa Pública "Corporación Extremeña de Medios Audiovisuales", entre otras.

En principio, en la Ley General de Comunicación Audiovisual, las cadenas de titularidad estatal tenían ante sí un texto con muchas indicaciones de orden general y mucho recorrido de desarrollo futuro sin el cual perpetuarían conceptos poco precisos de esta norma. Como ejemplos, la creación de una autoridad audiovisual que habrá de definir su espacio y ámbito de actuación territorial o la reformulación de los contenidos de interés general. Las autonómicas además deberían hacer frente a varias cuestiones: de un lado, ser rentables siendo ajenos a la inversión publicitaria; de otro, demostrar calidad del servicio impulsando la producción propia. Su presente, en aquel año, estaba marcado por los réditos negativos que había ido dejando tras de sí el proceso de digitalización en todas las estructuras de la producción, la fragmentación de audiencias y una cierta desconfianza en su modelo de gestión. Sin embargo, la fuerte crisis económica y la llegada al poder del Partido Popular han propiciado que en el desarrollo de la LGCA y en la redefinición del marco audiovisual español, se haya 
optado por no poner en marcha el Consejo Audiovisual, como autoridad televisiva y abrir la puerta a la privatización de la gestión de las televisiones públicas autonómicas. Por todo lo dicho, si se parte de la Ley de creación de la nueva Corporación RTVE, de 2006, nos estamos refiriendo a un periodo de tiempo de poco más de cinco años en el que se ha reformulado el modelo de servicio público de televisión en España.

\section{DESARROLLO}

\subsection{De la reforma de los medios de comunicación de titularidad estatal a la Ley General de lo Audiovisual}

La Reforma del Estatuto de la Radio y la Televisión de 1980 emergía como una prioridad dentro de las acciones del Gobierno para el periodo inmediatamente anterior al encendido digital.

En febrero de 2005, el Comité de Sabios ${ }^{2}$ presentó su Informe para la Reforma de los Medios de Comunicación de Titularidad del Estado, documento que, con ciertas modificaciones tras su paso por el Parlamento, constituyó la nueva Ley de Radio y Televisión Públicas (Ley 17/2006 aprobada el 11 de mayo de 2006). Los cambios más relevantes que marca esta ley se refieren a la independencia de RTVE con respecto al Gobierno, al pasar a convertirse en corporación y abandonar el estatus de ente público con un presidente elegido por el Congreso de los Diputados por mayoría de dos tercios para un periodo de seis años.

El Consejo Asesor seguirá estando compuesto por doce miembros -uno de los cuales será el Presidente de la Corporación- electos por el Parlamento español (ocho por el Congreso y cuatro por el Parlamento, por mayoría de dos tercios) para un periodo de seis años que no puede ampliarse pero que pueden renovarse parcialmente cada tres años.

Como se ha dicho, la nueva Ley de creación de la Corporación de RTVE se hace eco, en parte, de las propuestas del informe elaborado por el Consejo para la reforma de los Medios de Comunicación de titularidad del Estado, creado por el Real Decreto 744/2004, de 23 de abril. Sobre todo porque plantea la necesidad de una reforma para establecer un mecanismo de financiación estable y sostenido con el objeto de adecuarse a los principios de transparencia en la gestión del servicio público de radio y televisión, evitando un proceso de financiación del déficit corriente mediante el recurso al endeudamiento (Ortiz, 2010).

En cuanto al modelo de financiación ${ }^{3}$ se mantiene en la nueva Ley de creación de la Corporación el modelo mixto, bajo la atenta vigilancia de la Unión Europea, que ha

\footnotetext{
${ }^{2}$ El llamado Comité de Sabios fue el órgano encargado de asesorar al Gobierno del PSOE sobre las reformas necesarias para sanear RTVE (2004-2005). Retis, Jessica; Lamuedra, María y García Matilla, Agustín (2010). Los informativos diarios en BBC y TVE. Madrid: Ediciones de la Torre.

3 Otras medidas financieras importantes surgieron como resultado del Plan de Racionalización de la SEPI, tales como una reducción notable de la plantilla y del número de horas para programas en lenguas regionales que RTVE tiene en varias comunidades autónomas.
} 
obligado a que haya una cláusula que declare que la deuda abierta -que ha sido asumida por el Estado español- quede expresamente prohibida:

"La Corporación RTVE, sus sociedades prestadoras del servicio público y cualesquiera otras sociedades en las que posean, directa o indirectamente, la mayoría del capital social sólo podrán recurrir al endeudamiento para la financiación de sus inversiones en inmovilizado material e inmaterial y para atender desfases temporales de tesorería. Los límites de tal endeudamiento quedarán fijados, para cada ejercicio, en los correspondientes contratos-programa." 4

Al margen de su significado general, la Ley 17/2006 de 5 de junio tiene como objetivo prioritario ser la norma que dota a la radio y la televisión de titularidad estatal de un régimen jurídico que garantice su independencia, neutralidad y objetividad, estableciendo, además de los principios de regulación y prestación del servicio público, la estructura organizativa y funcional necesaria, y un modelo de financiación que les permita ejercer su función con eficacia, calidad y reconocimiento público. La nueva norma subraya una vez más, al igual que lo ya lo hiciera la Ley 4/1980, las diferencias en cuanto a misión y valores ${ }^{5}$ que separan el funcionamiento de las entidades públicas con respecto a los operadores privados. Dentro de la reafirmación del carácter de servicio público de estas corporaciones de titularidad estatal, la labor legislativa se cierne especialmente sobre la necesidad de modificar el modelo de gestión financiera de modo que su rentabilidad contribuya a la calidad de la prestación del servicio.

En este punto, la Ley 7/2010 de 31 de marzo, se muestra continuista con esa línea para lo que manifiesta "estar inmersa en el proyecto de reforma audiovisual del Gobierno". Ambas leyes sitúan el marco de referencia inicial en los preceptos constitucionales (artículo 20) y en el desarrollo legislativo posterior efectuado por los distintos Estatutos de Autonomía de las Comunidades Autónomas españolas.

La Ley 17/2006 reconoce en su Título I de forma explícita su objetivo de regular el servicio público de radio y televisión de titularidad estatal, y manifiesta su intención de establecer "el régimen jurídico de las entidades a las que se encomienda la prestación de dichos servicios públicos". Una vez definido este servicio de carácter esencial, se efectúa la encomienda a la Corporación RTVE para lo que se procede al mandato de creación de aquellos mecanismos de control de la gestión económica y de servicio público adecuados para asegurar transparencia y garantía en los derechos de los ciudadanos, especialmente a través de un Consejo Asesor, un Consejo de Informativos y la Comisión de Control Parlamentario (Título II, Capítulos II y III). La Ley apunta también la conveniencia de crear una autoridad audiovisual de control externo de la

\footnotetext{
${ }^{4}$ Ley 17/2006 de 5 de junio, artículo 31: Recurso al endeudamiento.

${ }^{5}$ La BBC habla de "valores editoriales" entre los que están la imparcialidad, la exactitud, la consulta de fuentes, etc. Ello se recoge en la guía editorial de la corporación donde se explican todos estos conceptos en el contexto amplio de servicio público. La BBC señala junto con estos conceptos, aquellos mecanismos que el editor tiene a su alcance para comprobar la producción y asegurar la calidad del servicio, incluso cuando éste es de pago. En el caso de RTVE, por ahora, el servicio público esencial se contempla de forma gratuita.
} 
actividad de la radio y televisión de titularidad estatal para supervisar las funciones para las que fue creada (mediante informes con carácter confidencial).

\subsection{El servicio público estatal de televisión}

El servicio público de radio y televisión del Estado ${ }^{6}$ definido en la Ley 17/2006, de 5 de junio, de la CRTVE, incluye una gama más amplia de servicios que los recogidos con carácter general para todo el sector por la posterior Ley 7/2010, de 31 de marzo, General de Comunicación Audiovisual. En concreto, en la primera se habla de "un servicio esencial para la comunidad y la cohesión de las sociedades democráticas que tiene por objeto la producción, edición y difusión de un conjunto de canales de radio y televisión con programaciones diversas y equilibradas para todo tipo de público, cubriendo todos los géneros y destinadas a satisfacer necesidades de información, cultura, educación y entretenimiento de la sociedad española; difundir su identidad y diversidad culturales; promover el pluralismo, la participación y los demás valores constitucionales, garantizando el acceso de los grupos sociales y políticos significativos" $^{7}$. La función de servicio público comprende, según este texto, la producción de contenidos y la edición y difusión de canales generalistas y temáticos, en abierto o codificados, en el ámbito nacional e internacional, así como la oferta de servicios conexos 0 interactivos, orientados a los fines señalados anteriormente. Asimismo, se señala expresamente que forma parte de esta función de servicio público "contribuir al desarrollo de la Sociedad de la Información", adaptando la tecnología necesaria y promoviendo los servicios interactivos para el ciudadano, evitando la discriminación por causa de discapacidad ${ }^{8}$. Al igual que los ciudadanos con algún grado de discapacidad, son objeto prioritario de este servicio, colectivos con riesgo importante de exclusión, público infantil y personas de la tercera edad.

En la Ley 7/2010, de 31 de marzo, la definición de servicio público se ciñe a “la comunicación audiovisual" entendido como:

un servicio de interés económico general que tiene como misión difundir contenidos que fomenten los principios y valores constitucionales, contribuir a la formación de una opinión pública plural, dar a conocer la diversidad cultural y lingüística de España, y difundir el conocimiento y las artes, con especial incidencia en el fomento de una cultura audiovisual. ${ }^{9}$ Los prestadores de este servicio atenderán a los ciudadanos y grupos sociales que no son destinatarios de la programación mayoritaria. El objeto del servicio público con respecto a la

\footnotetext{
${ }^{6}$ Este articulo se sitúa dentro del marco del proyecto de I+D+i: "I mpacto de Internet en la redefinición del servicio público de las televisiones públicas autonómicas españolas" (Referencia del proyecto: CSO2009-11250/SOCl), aprobado por el Ministerio de Ciencia y Tecnología para el periodo 2010-2013.

${ }^{7}$ Ley 17/2006 de 5 de junio. Título I, artículo 2.

${ }^{8}$ Este es uno de los puntos más importantes sobre los que el legislador quiere aprovechar el desarrollo tecnológico que supone la digitalización de todos los sistemas de comunicación y las posibilidades que ofrece a las personas con discapacidad para acceder a información y servicios como cualquier ciudadano.

${ }^{9}$ Ley $7 / 2010$ de 31 de marzo: Título IV, artículo 40.
} 
producción, edición y difusión de canales de radio y televisión aparece redactado de forma análoga a la ley de 2006, con la inclusión de 'servicios de información en línea.

La Directiva 2007/65/CE del parlamento Europeo y del Consejo, de 11 de diciembre de 2007, por la que se modifica la Directiva 89/552/CEE del Consejo sobre la coordinación de determinadas disposiciones legales, reglamentarias y administrativas de los Estados miembros relativas al ejercicio de actividades de radiodifusión televisiva, o "Servicios de medios audiovisuales sin fronteras", introduce la distinción entre servicios lineales y servicios no lineales. Los primeros designan los servicios de televisión tradicional, Internet y telefonía móvil que los telespectadores reciben pasivamente, y los segundos engloban los servicios de televisión a la carta. La influencia de internet en la re-formulación del servicio público en los medios de comunicación de titularidad del Estado queda asentada en la nueva LGCA desde su preámbulo cuando señala que "irrumpe Internet como competidora de contenidos" por lo que se hace necesaria una reordenación del sistema audiovisual.

Es importante en la nueva norma la defensa de este servicio plasmada en la prohibición de cesión a terceros de la producción y edición de los programas informativos y de aquellos que expresamente determinen los mandatos marco, encargados de elaborar la lista de eventos calificables de interés general, aunque como mas adelante se verá, el nuevo Gobierno ha dado luz verde a la externalización de la producción informativa de los canales públicos. En cuanto a contenidos prioritarios para el cumplimiento de esta función, en el mandato marco de RTVE se muestra prioridad por la protección de colectivos sociales como la tercera edad, los menores o la infancia, al tiempo que se incluye como objetivo la participación activa de la mujer.

En consonancia, se reservan espacios significativos a contenidos culturales, infantiles, deportivos (J uegos Olímpicos, motociclismo, fútbol, etc.), informativos, divulgativos y/o entretenimiento para todos los públicos (mención a magacines y reportajes), ficción, etc. Junto con los porcentajes de programación reservada para cada uno de los contenidos que configuran el servicio público, y que constituyen la base normativa para evitar la externalización de la producción ${ }^{10}$, se promueven por primera vez en el articulado las obras noveles, especialmente de jóvenes, así como las producciones nacionales.

Según la Ley General de Comunicación Audiovisual, el desarrollo y concreción de la función de servicio público audiovisual tendrá lugar cuando el Gobierno firme el correspondiente contrato programa con RTVE (en el plazo máximo de 180 días desde la entrada en vigor de la ley) para el cumplimiento de lo estipulado en los artículos 2 y 3 de la Ley 17/2006 de 5 de junio y en el artículo 9 de la Ley 8/2009 de 28 de agosto, sobre la financiación de la corporación.

\footnotetext{
${ }^{10}$ Sobre este importante aspecto volveremos en el punto 5.
} 
Uno de los aspectos reflejados en la LGCA más novedosos en cuanto al cumplimiento del servicio público es la posibilidad de suscribir acuerdos entre prestadores públicos cuando se trate de emitir en abierto canales generalistas no temáticos (Artículo 40.2) y la emisión de este servicio por una Comunidad o Ciudad Autónoma en otra limítrofe con afinidades lingüísticas y culturales, mediante convenio (Artículo 40.3). Éste último precepto abre la posibilidad de que varias entidades públicas autonómicas o locales acuerden la difusión de contenidos en sus respectivos territorios con lo que ello supone de aumento de la programación, disminución de la producción propia de cada una de las implicadas e incluso de homogeneización programática, en lugar de pluralismo y diversidad. Es, además, una posibilidad plausible por cuanto supone de salvavidas para muchas entidades que ven peligrar su supervivencia en el actual escenario de encendido digital y desarrollo de la TDT, la HDTV y la DVB-H.

El artículo 40 de la Ley General de Comunicación Audiovisual es el que más ampliamente menciona a las Comunidades Autónomas confiriéndoles un papel de responsabilidad de la prestación del servicio público al unísono con el de RTVE. Los paralelismos son, empero, más evidentes en las función de control de estos organismos por parte del Parlamento, a través de los contratos programa que han de firmar para periodos inferiores a los nueve años para los que se establecen normativamente los objetivos generales del servicio público ${ }^{11}$.

Los límites para los prestadores de servicio público audiovisual de titularidad pública se recogen en el artículo 42 de la Ley General, donde destacan la prohibición de participar en el capital social de prestadores privados del servicio de comunicación audiovisual, la mención expresa a que la gestión de éstos deberá realizarse conforme a criterios de transparencia empresarial, el anuncio de la creación de un órgano de control de la prestación del servicio público, y restricción a un $25 \%$ del espacio radioeléctrico para su actividad:

En el ámbito de cobertura estatal, el Estado no podrá reservar o adjudicar a los prestadores de titularidad pública más del 25 por ciento del espacio radioeléctrico disponible para el servicio de televisión en el ámbito estatal, de acuerdo con el Plan Técnico Nacional correspondiente. En el caso de las emisoras radiofónicas de ámbito estatal, el Estado no podrá reservar a los prestadores de titularidad pública estatal más del $35 \%$ del espacio radioeléctrico disponible para el servicio de radiodifusión, de acuerdo con el Plan Técnico Nacional correspondiente. ${ }^{12}$

\footnotetext{
${ }^{11}$ El contrato programa de la Corporación RTVE fue presentado por el entonces Director de RTVE, Luis Fernández, en 2008, para un periodo inicial de tres años y en él se contemplaba especialmente el modo de financiación, control y gestión externa de la radio televisión estatal, así como el porcentaje de los géneros de programación por cada uno de los canales generalistas de titularidad estatal.

${ }_{12}$ Ley 7/2010 de 31 de marzo General de la Comunicación Audiovisual, artículo 42: 4.
} 


\subsection{Un cambio en las estructuras}

La organización tanto estructural como de control de la Corporación RTVE, unido al artículo 42 de esta misma Ley (por la que se prevén la posible desaparición de la corporación, su fusión o adquisición, con el único permiso del Consejo de Ministros) rompe el blindaje que suponía la Ley 4/1980 de 10 de enero que, a pesar de depositar en manos del Gobierno varias facultades de control del ente público que pasan ahora al Parlamento, no disponía en ningún momento la posibilidad de que los medios de titularidad pública pudieran cambiar de naturaleza jurídica. Si el anterior Estatuto de la radio y la televisión de 1980 constituía "las normas básicas del régimen de los servicios públicos de radiodifusión y televisión que serán de aplicación en todo el territorio nacional" (Título I, Artículo II.1) y queda derogado por efecto de esta reforma, parece plausible pensar que la voluntad legislativa es de sustitución efectiva de la una por la otra, cuestión que se ve subrayada por la profusión con la que en la Ley 17/2006 se especifican las funciones de servicio público, organización mercantil, conversión laboral del personal, mecanismos de control interno y externo, etc. La Ley 7/2010 de 31 de marzo se muestra, de nuevo, además de continuista con ésta, más preocupada por el establecimiento de pautas que aseguren la transparencia empresarial y aumenten la seguridad jurídica de las empresas audiovisuales, sin perjuicio de los derechos y garantías que corresponden a los ciudadanos.

Así lo entendieron la TVC y el CAC quienes criticaron duramente el Proyecto de Ley cuando fue aprobado en 2009 por el Consejo de Ministros. El sector audiovisual catalán representa casi un tercio del total del negocio audiovisual de toda España y es, además, el más regulado ${ }^{13}$. El presidente de la CCMA, Albert Sáez, consideraba que la Ley General era una norma "incompatible" con las leyes catalanas que regulan este sector en la actualidad ${ }^{14}$. La creación de una autoridad audiovisual nacional (CEMA), o la Agencia del Cine, podía considerarse una intromisión en las decisiones de los respectivos consejos autonómicos, como es el caso del catalán, máxime tratándose, como es el caso, de un órgano sancionador.

La Ley General de la Comunicación Audiovisual sigue las directrices de interpretación de algunos conceptos marcados y definidos por el extinto Estatuto de Radio y Televisión, al continuar nombrando a los medios de comunicación audiovisual en términos de radiodifusión y televisión. Aunque presenta la novedad de incluir "los servicios interactivos", no está claro si contempla Internet como medio audiovisual o como servicio de valor añadido a la radio y la televisión.

De acuerdo con lo fijado en el primer mandato marco de la Corporación RTVE, de 7 de diciembre de 2007, por el que se concretan los objetivos generales y líneas estratégicas del servicio público esencial de la radio y televisión de titularidad estatal (con una vigencia de 9 años), y los términos del contrato programa presentado en 2008 con el Gobierno por tres años, con el objetivo de sanear las cuentas de la

\footnotetext{
${ }^{13}$ La CCMA, que engloba la televisión y la radio públicas catalanas, cuenta con su propia ley reguladora y su propio consejo audiovisual, el CAC.

${ }^{14}$ www.elmundo.es/elmundo/2009/11/10/barcelona/1257876033.html (Consultado en mayo de 2010).
} 
entidad, parece evidente que el modelo normativo que se desprende de esta reforma es el que habrían de seguir las radio-televisiones autonómicas por cuanto son las entidades depositarias de la misión de servicio público en las respectivas CCAA según determinaba la Ley 4/1980 en su Artículo II.b, desarrollado posteriormente en los actuales Estatutos de Autonomía y que la actual normativa corrobora. La Ley 7/2010 incluye a estas entidades, cuestión que no hacía la ley de 2006, y lo hace para alinear sus derechos y responsabilidades en el ejercicio de sus funciones hacia el ciudadano (como garante de sus derechos de información y acceso a contenidos audiovisuales ${ }^{15}$ ). Sin embargo, como antes se ha mencionado, la propuesta de modificación de la Ley del Tercer Canal y la apertura de la posibilidad de privatización de las televisiones autonómicas propuesta por el nuevo Gobierno del Partido Popular para el 2012, replantea sin duda los presupuestos iniciales de la Ley.

\subsection{Un nuevo modelo de financiación}

A partir de ahora, una vez aprobada la Ley 8/2009 de Financiación de RTVE, la Corporación se debe financiar a través de aportaciones del Estado y otras aportaciones obtenidas de la siguiente manera (J ivkova, 2011):

a) Los operadores de televisión comercial que operan a nivel estatal o en más de una Comunidad Autónoma aportarán anualmente un 3\% de sus ingresos brutos. La aportación para la televisión de pago está fijada en el 1,5\%. Los operadores de telecomunicaciones, también según el mismo criterio territorial, aportarán, por su parte, un $0,9 \%$ de sus ingresos brutos de explotación facturados en el año correspondiente, excluidos los obtenidos en el mercado de referencia al por mayor.

b) La Corporación RTVE percibirá el 80 por 100 de lo recaudado por la tasa sobre reserva de dominio público radioeléctrico regulada en la Ley General de Telecomunicaciones.

c) La radiotelevisión pública contará también con los ingresos obtenidos por el ejercicio de sus actividades y por la comercialización de sus servicios y productos.

Una de las consecuencias más mencionadas ha sido la eliminación de la publicidad de la programación televisiva, línea que puso en marcha anteriormente en Francia Nicolás Sarkozy. La Ley española reconoce al Estado, las Comunidades Autónomas y las Entidades Locales como aquellas legitimadas para, en el ámbito de su competencia, determinar el sistema de financiación de su servicio público de comunicación audiovisual, aunque recorta la publicidad:

Los servicios de interés económico general de comunicación audiovisual radiofónica, televisiva, conexos e interactivos de titularidad estatal no admitirán ninguna forma de comunicación comercial audiovisual, ni la emisión de

\footnotetext{
${ }^{15}$ Es importante en este punto la constancia expresa (Título IV) del fomento de la diversidad lingüística y cultural.
} 
contenidos audiovisual en sistemas de acceso condicional, sin perjuicio de las excepciones que su normativa específica de financiación establezca.....Los prestadores de televisión de titularidad pública no podrán dedicar canales exclusivamente a emitir comunicación comercial. ${ }^{16}$

La retirada de la financiación publicitaria es, sin embargo, una medida que genera problemas inmediatos para las arcas de las cadenas públicas que se ven abocadas a pedir dinero a organismos superiores. El 25 de junio de 2008, el presidente francés, Nicolás Sarkozy, anunció la progresiva supresión de la publicidad en la televisión pública francesa a partir del 1 de enero de 2009, que sería financiada con gravámenes a los operadores de telefonía e internet y a los ingresos publicitarios de las cadenas privadas (modelo que supuso una fuente de inspiración para el Ejecutivo español):

Recientemente, el Tribunal General de la Unión Europea ha determinado que la ayuda estatal de 150 millones de euros concedida al ente público de televisión francés en 2008 tras el anuncio de la supresión de las emisiones publicitarias es compatible con el derecho europeo ${ }^{17}$. Con esta sentencia, el tribunal da la razón a la Comisión Europea, que el 16 de julio de 2008 autorizó esta dotación de capital por considerar que estaba destinada a cubrir los costes del servicio público prestado por France Télévisions, propietaria de las cadenas France 2, France 3, France 4, France 5, France Ô y RFO.

La Comisión Europea abrió un procedimiento contra Francia por la tasa impuesta a los operadores de telecomunicaciones, que se calcula sobre su cifra de negocio y se impone como condición para concederles el permiso para operar. España tiene abierto un procedimiento similar sobre la tasa impuesta a los operadores de telecomunicaciones para compensar la supresión de la publicidad de pago en Radiotelevisión. La Comisión Europea considera que esta tasa ${ }^{18}$ podría ser incompatible con la legislación comunitaria sobre telecomunicaciones y perjudicar indebidamente a los operadores, limitando las inversiones en nuevas redes y afectando negativamente a los clientes. Según la propia Comisaria europea de Telecomunicaciones, Neelie Kroes, "A la Comisión le preocupa que este nuevo gravamen pueda "limitar sus inversiones en nuevas redes y servicios avanzados y penalizando en definitiva a sus clientes". ${ }^{19}$

La Asociación Española de Operadores de Telecomunicaciones con Red Propia (Redtel) -que agrupa a ONO, Orange, Telefónica y Vodafone- siempre se ha mostrado en contra de esta medida. En otros países como Alemania, la televisión

\footnotetext{
${ }^{16}$ Ley 7/2010, General de la Comunicación Audiovisual, Artículo 43: 1 y 2.

${ }^{17}$ La sentencia desestima los recursos impuestos por las cadenas privadas de la competencia Métropole télévision (M6) y Télévision française 1 (TF1), que había solicitado la anulación de la decisión del Ejecutivo comunitario.

${ }^{18}$ El nuevo modelo suprime la publicidad en TVE y obliga a los operadores de telefonía a contribuir a la financiación de la televisión pública con el $0,9 \%$ de sus ingresos, a las cadenas privadas a aportar el $3 \%$, y a las de pago el $1,5 \%$.

${ }^{19}$ www.telecinco.es/telemania/detail/detail23758.shtml (Consultada el 10 de julio de 2010).
} 
pública se financia con los cánones que paga la audiencia a través de un impuesto directo. Es obligación de cada hogar declarar cada televisor y radio y, de ese número, se determina una cuota a pagar trimestralmente. La suma varía de acuerdo al estado, pero actualmente se estima que ronda los 40 euros por un televisor y una radio ${ }^{20}$. " $\mathrm{La}$ gente ya está concientizada y, en general, no se opone al impuesto. Pero ese aporte nos obliga a hacer una televisión de excelente calidad y, si no están conformes, nos lo hacen saber", señala Carlos Delgado, productor ejecutivo de Deutsche Welle en Berlín.

Desde el Ejecutivo español, Fernando Castillo, subdirector general de medios audiovisuales en el Ministerio de Industria en 2010, reconoció que la nueva regulación, que supondrá un importante impacto en el mercado publicitario, precisa de una clasificación más exacta, en la que ya trabaja el Ministerio, de formatos como la telepromoción, autopromoción, televenta, patrocinio u otras fórmulas publicitarias en relación con el tiempo tope de publicidad por hora y las nuevas reglas de las interrupciones de los programas para incluir publicidad. ${ }^{21}$

Por último, y con el fin de cuantificar el coste neto del servicio público de comunicación audiovisual, se aboga desde el articulado por una gestión transparente, con cuentas separadas que informen a los órganos correspondientes, de la capacidad de generar y mantener el negocio y de la calidad del servicio ofrecido:

los prestadores de este servicio deben disponer de separación de cuentas por actividades así como llevar un sistema de contabilidad analítica que separe la imputación de ingresos y costes de la actividad de servicio público, de los contenidos comerciales y de las restantes actividades. Igualmente, los prestadores del servicio público de comunicación audiovisual deberán proceder progresivamente a la separación estructural de sus actividades para garantizar los precios de transferencia y el respeto a las condiciones de mercado. Todo ello conforme a lo dispuesto en la Ley 4/2007, de 3 de abril, de Transparencia. ${ }^{22}$

La autoridad audiovisual competente determinará un procedimiento de control periódico de la financiación pública que reciban los prestadores del servicio público de comunicación audiovisual, así como las medidas de reequilibrio necesarias para que su destino sea el establecido en la Ley.

De nuevo, en consonancia con las "recomendaciones" de la Comisión Europea sobre la aplicación de las normas en materia de ayudas estatales a los servicios públicos de radiodifusión, se determina que:

\footnotetext{
${ }^{20}$ En Alemania están dados de alta, a finales de 2009, más de 37 millones de televisores.

${ }^{21}$ www.panoramaaudiovisual.com. (Consultada sección Televisión, 5 de junio de 2010).

22 Ley 7/2010, General de la Comunicación Audiovisual, Artículo 43: 5.
} 
los prestadores de servicios públicos de comunicación audiovisual no podrán sub-cotizar los precios de su oferta comercial y de servicios ni utilizar la compensación pública para sobrepujar frente a competidores privados por derechos de emisión sobre contenidos de gran valor en el mercado audiovisual. ${ }^{23}$

\subsection{La televisión de servicio público ante la práctica de externalizar la producción}

Una de las funciones que se ha atribuido a las televisiones de servicio público, y muy en particular, a las televisiones públicas autonómicas, es la de contribuir a la creación del tejido industrial audiovisual en su ámbito geográfico de cobertura. Es decir, allí donde una televisión pública se implanta, genera una demanda de servicios y de productos audiovisuales que anima a la iniciativa privada a crear empresas para ofrecerlos. En este sentido, se comprueba que en las comunidades autónomas donde la televisión pública ha adquirido una dimensión notable -como es el caso de la Corporación de Medios de Comunicación de Cataluña, y de Euskal Telebista, en el País Vasco- la red de productoras privadas que elaboran productos de entretenimiento, de comunicación comercial, y en algún caso también de carácter informativo, es mucho mayor ${ }^{24}$ (Observatori de la Producció Audiovisual, 2010) y de más envergadura que en aquella regiones que, o no tienen una televisión pública autonómica, o la que existe es de creación reciente.

Sin embargo, son la mayoría de las televisiones autonómicas de última generación las que tienen externalizados muchos de sus contenidos, incluidos los informativos. Eses es el caso, por ejemplo, de las televisiones autonómicas de Canarias, Aragón, Baleares y Murcia, que han cedido a empresas privadas la realización de telediarios, espacios de reportajes, y grandes magacines matinales. Esta fórmula les ha permitido ajustar las plantillas y ahorrar costes. Una práctica que en el caso de TVE sólo ha afectado a la producción de programas pero no a la producción informativos, de momento. Si bien es cierto que, en algunos casos, se ha bordeado la externalización de este tipo de contenidos como ocurrió con el caso de la producción del porgada "España Directo" que fue encomendado a la productora Mediapro.

De Moragas y Prado (De Moragas y Prado, 2001) defienden que, en el actual contexto digital, ha aumentado la necesidad de tejido industrial audiovisual que surta las necesidades de programas de las televisiones públicas:

Los ciudadanos que pueden acceder a un amplio repertorio de productos audiovisuales sólo escogerán el contacto con los de producción doméstica si son gratificantes. Únicamente la existencia de programas de calidad y competitivos, portadores de valores culturales y marcas de identidad, permitirá a la televisión pública cumplir con sus finalidades como instrumento de dinamización cultural y

\footnotetext{
${ }^{23}$ Ley 7/2010, General de la Comunicación Audiovisual, Artículo 43: 9.

24 Informe del OBSERVATORI DE LA PRODUCCIÓ AUDIOVISUAL, publicado en enero 2010, La producción catalana en la televisión" recuperado el 14 de julio de 2010, en www.upf.edu/opa, p. 9-15.
} 
social. Casado (Casado, 2007, p. 529), desde otro punto de vista, afirma que todas las estrategias de fortalecimiento de la industria audiovisual en las comunidades autónomas, pasan por un apoyo firme de las televisiones autonómicas (públicas) a las empresas locales.

En definitiva: las televisiones públicas autonómicas necesitan de la existencia de una industria audiovisual de cercanía, que sea capaz de ofrecerle una variedad de productos audiovisuales de calidad; $y$, a la vez, para que esas empresas elaboren productos con marca de identidad cultural y social requieren de una específica vinculación con las televisiones públicas autonómicas.

Desde una perspectiva más amplia, Alm y Ferrel Lowe (Alm y Ferrel Lowe, 2003, p. 231-232) apuntan a tres argumentos favorables a la externalización en las televisiones públicas, conscientes, eso sí, de que debe tener una medida razonable:

Primero (...) debe comprenderse que externalizar en alguna medida también tiene sus argumentos a favor: se apoya al sector audiovisual independiente, se cultiva nuevo talento y se estimula el desarrollo audiovisual local y regional; en segundo lugar se facilita el ahorro de costes por vía de coproducciones, con la correlativa menor necesidad de contratación indefinida en la televisión; por último, asegura mejor a la televisión pública centrarse en la producción que implique más sus competencias esenciales como televisión de servicio público.

\subsubsection{Razones para limitar la externalización}

A pesar del reconocimiento generalizado del papel de las televisiones públicas en una promoción de la industria audiovisual, cada vez son más las voces críticas sobre el modo en que este impulso se lleva a cabo. Sus argumentos se basan principalmente en dos motivos:

1. Las televisiones públicas autonómicas resultan ser los únicos consumidores de los productos audiovisuales locales y "esto genera una grave situación de dependencia por parte de los productores que resulta casi insalvable" si se tiene en cuenta el tamaño de la mayoría de las productoras ${ }^{25}$. Además, las productoras han actuado, "más pensando en la obtención de beneficios a corto plazo, como contraprestación a sus servicios profesionales, que en una estrategia de consolidación empresarial que les permita actuar como una pieza independiente en la industria audiovisual' ${ }^{\prime 26}$. El resultado es una industria poco competitiva, tal y como la relación televisión pública-productoras que le surten está planteada.

\footnotetext{
${ }^{25}$ Ibidem, p. 527.

26 De Moragas, M. y Prado, E., op.cit. notas anteriores. En la misma línea Fernández-Quijada refiriéndose específicamente al caso andaluz, en Producción Independiente de Televisión en Andalucía. Aproximación a la estructura de un sector desconocido en Revista Ámbitos n. 18, 2009, p.201.
} 
2. El exceso de consumo de programas provenientes de productoras privadas, por parte de las televisiones públicas, puede dar lugar a la descapitalización de los servicios propios de los entes audiovisuales públicos. Así, en España, a lo largo de este año 2010, han sido frecuentes las protestas de los profesionales de las televisiones públicas por este motivo, al ver que se encargaban a empresas externas lo que muy bien podían haber efectuado ellos mismos desde los departamentos de las televisiones.

Como casi siempre, combinar los dos objetivos de la televisión pública, por un lado, fomentar la industria audiovisual local, y por otro, ofrecer programas de calidad que respondan a la identidad cultural y social de una comunidad autónoma, exige lograr un difícil equilibrio. Las televisiones públicas autonómicas deben implicarse en las empresas audiovisuales locales, pero no hasta el punto de que éstas se limiten a hacer programas por encargo de la televisión pública cercana, sin arriesgarse financieramente" y, en consecuencia, sin obtener los derechos de explotación de sus propias producciones:

La televisión pública entre sus funciones de servicio tendría que promover que emerjan iniciativas, seleccionando las de más calidad, rigor empresarial, hacer una cierta transferencia de su 'saber hacer' en producción y compartir los derechos de las escalas de comercialización ajenas a la emisión propia (salas, videoclubes, ppv, canales de pago y ventas al mercado exterior). Todo esto a cambio de un derecho preferente de adquisición a precio de mercado, de la primera producción autónoma de aquella productora independiente. (Moragás y Prado, 2001).

\subsubsection{La limitación legal para externalizar la producción en la Ley General de la Comunicación Audiovisual, de 2010}

La Ley española 7/2010, de 31 de marzo, "General de la Comunicación Audiovisual" prohíbe de forma explícita la externalización de programas informativos en las televisiones públicas y limita esa posibilidad para el resto de contenidos, en la medida en que establece que será en el mandato marco de cada televisión pública donde se extienda esa prohibición a otro tipo de programas. Al mismo tiempo se impulsa la producción propia como vía óptima para las televisiones de servicio público: Art. 40.1

(...) "Los entes que presten el servicio público de comunicación audiovisual y sus sociedades prestadoras no podrán ceder a terceros la producción y edición de los programas informativos y de aquellos que expresamente determinen los mandatos marco que para cada ente se aprueben en desarrollo del marco competencial correspondiente. Igualmente, impulsarán la producción propia de su programación de forma que ésta abarque la mayoría de los programas difundidos en las cadenas generalistas. 
¿Qué se entiende aquí por programa informativo? ¿sólo los telediarios o habrá que considerar que también son programas informativos los documentales, reportajes de investigación, magazines que incluyen piezas de entretenimiento pero que en su mayor parte del tiempo constan de entrevistas, debates y comentarios de prensa? Los programas de éxito comprados a productoras independientes tipo "Euskadi directo" de ETB del País Vasco, "España directo" de TVE, "Galegos no mundo" de TVG de Galicia, "Españoles en el mundo" de TVE ¿cabrían entre los programas de sólo entretenimiento? ¿o no pueden calificarse como programas informativos? Si se analizan los aspectos implicados en la relación operador público de televisiónproductora privada que suministra contenidos, la obligación de producir con los propios equipos los informativos garantiza no sólo independencia para las televisiones públicas, sino también calidad, tal y como describen De Mateo y Bergés (De Mateo y Bergés, 2009, p. 201):

la opción de producción propia de las televisiones públicas se justifica en criterios de calidad de la cobertura informativa, que se hace menos dependiente de proveedores externos, se puede ajustar mejor a los requerimientos de calidad propios - selección de la información, uso de fuentes propias, criterios propios de tratamiento de la información-. También, el mayor volumen de inversión en equipos propios otorga una mayor capacidad de producción que se refleja en una oferta informativa más amplia y variedad.

En cualquier caso, la externalización es un hecho invasivo, tal y como lo demuestran algunos datos. En mayo de 2010, salió a la luz la noticia de que "Overon" una filial del grupo "Mediapro" había producido 784 de los " 6.618 brutos y piezas manejados por los diferentes programas informativos de TVE en los tres primeros meses" de $2010^{27}$. La cifra varía entre las televisiones públicas autonómicas: algunas alcanzan hasta un $18,12 \%$ de su programación, como ocurre con ETB del País Vasco, en 2005-2006, mientras otras como la TVG de Galicia, sólo indica un 2,36\% para el mismo periodo.

Es una filosofía de gestión de las televisiones públicas, la estatal y las autonómicas, que se ve en contradicción con lo establecido como principio por la Ley 7/2010, General de la Comunicación Audiovisual. Lo que ocurre es que las ventajas de la externalización, ya sea aplicada a empresas de televisión públicas o a empresas televisivas privadas, hace que sea casi inevitable recurrir a ella en alguna proporción, porque:

Al convertir las decisiones de inversión en decisiones de comprar, la empresa se ahorra, no sólo gastos de inversión, sino también gastos de mantenimiento, evita problemas de obsolescencia, reduce necesidades de control de procesos y

\footnotetext{
${ }^{27}$ Publicado en El Confidencial de 25 de mayo de 2010. Disponible en: www.elconfidencial.com/comunicacion/mediapro-tve-telediarios-produccion-propia-oliart20100526.html. (Consultado el 20 de julio de 2010)
} 
de desgaste, y ajusta de forma más flexible la capacidad productiva a las exigencias de producción" (De Mateo y Bergés, 2009, p. 201).

\subsubsection{Hacia un cambio de modelo en el nuevo desarrollo de de la Ley General de lo Audiovisual}

El anteproyecto de reforma de Ley General de Comunicación Audiovisual además de permitir a las comunidades autónomas elegir qué modelo prefieren para gestionar sus televisiones públicas --si uno público, privado o mixto--, abre la puerta a la externalización de los informativos y elimina la obligatoriedad de que la mayoría de la programación de las públicas sea de producción propia.

El texto del anteproyecto elimina los párrafos de la Ley General de Comunicación Audiovisual en los que se obligaba a los entes públicos a impulsar la producción propia de su programación "de forma que ésta abarque la mayoría de los programas difundidos en las cadenas generalistas". Asimismo, se retira de la Ley el párrafo en el que se prohibía explícitamente a los entes "ceder a terceros la producción y edición de los programas informativos y de aquellos que expresamente determinen los mandatos marco que para cada ente se aprueben en desarrollo del marco competencial correspondiente".

En ambos casos, la LGCA se refiere al conjunto de los entes públicos, incluidos RTVE, por lo que la eliminación de la norma teóricamente afecta, también, a TVE, aunque el funcionamiento de la cadena pública estatal está regulado por un conjunto de leyes, entre ellas la Ley de Radio y la Televisión de Titularidad Estatal y la Ley de Financiación de la Corporación de Radio y Televisión Española, que aseguran su gestión pública, y que no han sido modificadas.

\subsection{El nuevo marco legal del audiovisual y las autonómicas españolas}

En el panorama televisivo actual, con la presencia de nuevos operadores, las cadenas autonómicas han de hacer frente a una dura competencia entre más oferta de contenidos y más canales, especialmente privados. Las televisiones autonómicas agrupadas en la FORTA tienen una cobertura estimada del 88,6\% del territorio nacional, su audiencia potencial es de 37,6 millones de españoles, y la cuota media de mercado ronda el $15 \%$ desde el año 2007. El pilar básico de este modelo de operador es la proximidad al público. Desde ese mismo año, las cadenas autonómicas dedican un $40 \%$ más de programación al cine que el grupo de nacionales y un $32 \%$ más a contenidos de carácter cultural, sin olvidar la especial atención a los más pequeños con contenedores específicos tanto en castellano como en lengua propia, y las apuestas por las producciones de ficción propias: "Todo ello pone de relieve el insustituible papel de las de las televisiones autonómicas, protagonistas de un fenómeno de comunicación sin el cual nuestro entorno cultural y social sería totalmente distinto". 28

\footnotetext{
${ }^{28}$ Reunión de la FORTA en Oviedo: octubre de 2008.
} 
Las radios y televisiones autonómicas están configuradas como servicios públicos e inspiradas en los principios de objetividad, imparcialidad y veracidad de las informaciones, en el respeto al pluralismo político, religioso, social, cultural y lingüístico, el respeto a todas las libertades que reconocen la Constitución y los diferentes estatutos de autonomía, la protección de la infancia y la juventud y la separación entre información y opinión. Tienen, además, el objetivo principal de atender a la más amplia audiencia y el compromiso de ofrecer calidad, diversidad, innovación y exigencia ética, desde una perspectiva de proximidad pero con una visión universal, así como prestar atención a los asuntos de especial interés público y desarrollar nuevos servicios conexos o interactivos. La experiencia de las radios y televisiones autonómicas ha puesto de manifiesto también que han sido y están siendo herramientas fundamentales en el desarrollo de la estructura autonómica del Estado, especialmente en lo que supone la cohesión territorial y social de cada Autonomía, el desarrollo y difusión de las culturas -y las lenguas- propias, la presencia y proyección de los municipios y colectivos sociales de cada región y, en definitiva, la personalidad e identidad de cada comunidad autónoma. Además, en cada comunidad se ha generado, y continúa haciéndolo, un tejido industrial y empresarial importante del sector audiovisual.

La aprobación de la Ley General de la Comunicación Audiovisual de 31 de marzo de 2010 afecta normativamente a estas entidades por cuanto deroga la llamada Ley de los Terceros Canales, génesis de la actual disposición radiotelevisiva autonómica, como parte fundamental del desarrollo constitucional en materia de derechos de los ciudadanos. Desde algunas radiotelevisiones públicas autonómicas, se considera que el nuevo marco jurídico representa una clara tendencia a la desregularización y liberalización del sector.

Uno de los aspectos que más cambios tuvo durante la tramitación parlamentaria del nuevo texto es el que fija que los prestadores del servicio televisivo de cobertura estatal o autonómica deben contribuir anualmente a la financiación anticipada de la producción europea de películas y series, así como documentales y películas y series de animación, con el $5 \%$ de los ingresos devengados en el ejercicio anterior, índice que se eleva al $6 \%$ para los prestadores de titularidad pública. Como mínimo, el 60\% de esta obligación de financiación, y el $75 \%$ en los prestadores públicos, deberá dedicarse a películas cinematográficas. De esta inversión, por lo menos la mitad deberá aplicarse a obras de productores independientes. Del $40 \%$ o el $25 \%$ restante, en el caso, la mitad deberá ser películas o miniseries para televisión. En todo caso, el $60 \%$ de la financiación conjunta previsto en este artículo se destinará a la producción en alguna de las lenguas oficiales de España.

Sin embargo, en el anteproyecto de Desarrollo de la Ley General de Comunicación Audiovisual se incorpora un nuevo párrafo en el que se afirma que "las comunidades autónomas determinarán los modos de gestión del servicio público de comunicación audiovisual, que puede consistir, entre otras modalidades, en la gestión directa, en la gestión indirecta o en diferentes instrumentos de colaboración público-privada".

En la exposición de motivos, se afirma que 
la situación económica y la necesidad por parte del conjunto de las administraciones públicas de acometer actuaciones que faciliten la consolidación presupuestaria y el saneamiento de las cuentas públicas, aconseja proporcionar a las comunidades autónomas una mayor flexibilidad en la gestión de su servicio público de comunicación audiovisual.

En este sentido, justifica la eliminación de "determinadas limitaciones existentes" en la Ley Audiovisual relacionadas con "la cesión a terceros de las funciones de la producción y edición de determinados programas", así como la introducción de una "mayor flexibilidad" en la naturaleza de los entes públicos que presten el servicio público de comunicación audiovisual.

Así, con las modificaciones introducidas en la LGCA, las Comunidades Autónomas dispondrán de distintas alternativas para elegir el modelo de gestión de sus televisiones públicas, ya sea la gestión directa, una gestión indirecta a través de una persona privada o diferentes instrumentos de colaboración público-privadas, aunque la ley no detalla en qué consistirán estos instrumentos.

El futuro del servicio público de televisión prestado desde las Comunidades Autónomas está lleno de incógnitas. Mientras que los responsables políticos de algunas Comunidades Autónomas, como Madrid o Castilla-La Mancha, ya se han mostrado partidarios de acogerse al nuevo modelo y abrir la puerta de la privatización de sus televisiones, otros como Andalucía se han mostrado absolutamente en contra de la privatización, y algunos - como el Principado de Asturias- ha optado directamente por la asfixia económica. En paralelo, desde el partido del Gobierno empiezan a barajar la idea de un único canal con desconexiones territoriales, un proyecto vago y poco definido cuyo es objetivo es hacer más económica su gestión y reducir el número de competidores públicos.

\section{CONCLUSIONES}

Desde 1980, la televisión pública en España había venido fundamentándose en el Estatuto de la Radio y la Televisión de 1980 y el la Ley del Tercer Canal. La Ley de Creación de la nueva CRTVE primero, en 2006, la posterior publicación de la Ley General de Comunicación Audiovisual, en 2010, y ahora el desarrollo de dicha ley y la apertura a un nuevo modelo gestión de las televisiones públicas autonómicas, han propiciado una reformulación del modelo de televisión pública en España que, en 2012, empezarán a sentar sus bases.

\section{REFERENCIAS}

Alm, A. \& Ferrel Lowe, G. (2003). Outsourcing core competencies?, en Ferrel Lowe, G., Hujanen T., (eds.), Broadcasting \& convergence: New Articulations of the Public Service Remit. Göteborg: Nordicom, p. 223-235. 
Casado, M. A. (2007), La televisión autonómica y la promoción de la industria audiovisual local, en MORENO, E., y otros (ed.) Los desafíos de la televisión pública en Europa. Pamplona: EUNSA, p. 521-540.

De Mateo, R. \& Bergés, L. (2009). Los retos de las televisiones públicas. Financiación, servicio público y libre mercado. Sevilla-Zamora: Comunicación Social.

De Moragas, M. \& Prado, E. (2010). Repensar la televisión pública en el contexto digital, 2001 en el "Portal de la Comunicación" Consultados el 12 de julio de 2010, Disponible en: www.portalcomunicacion.com/esp,

Directiva Servicios de medios audiovisuales sin fronteras (2007). 2007/65/CE del Parlamento Europeo y del Consejo de 11 de diciembre de 2007.

Fernández-Quijada, D. (2009). El mercado de producción independiente en España ante la aparición de Cuatro y la Sexta, en Revista Comunicación y Sociedad. Vol. XXII, n.1, p. 59-87.

Farnández-Quijada, D. (2009). Producción Independiente de Televisión en Andalucía. Aproximación a la estructura de un sector desconocido, en Ámbitos, № 18, p. 191209.

Jivkova Semova, D. (2011). RTVE sin publicidad: un modelo de financiación en estado de emergencia, en Revista de Comunicación Vivat Academia, no 116 de septiembre de 2011. Madrid.

Análisis de la nueva ley general de la comunicación audiovisual (31 de marzo, 2010). Instituto de fomento Empresarial, en colaboración con Panorama Audiovisual, 1 de junio de 2010 (Madrid). Consultado el 18 de Junio del 2011, Disponible en: www.panoramaaudiovisual.com.

Observatorio de la producción audiovisual (2010). La producción catalana en la televisión. Consultado el 18 de Junio del 2011, Disponible en: www.upf.edu/opa

Ortiz Sobrino, M. Á. (2010): El nuevo marco legal para la financiación de la radiotelevisión pública estatal en España en revista Comunicación y Hombre.

Impacto de Internet en la redefinición del servicio público de las televisiones públicas autonómicas españolas. En: proyecto de investigación, I+D+i: CSO2009-11250/SOCI), aprobado por el Ministerio de Ciencia y Tecnología para el periodo 2010-2012. IP, Juan Carlos de Miguel Bustos.

Retis, Jessica, Lamuedra, María \& García Matilla, Agustín (2010). Los informativos diarios en BBC y TVE. Madrid: Ediciones de la Torre. 


\section{Nereida López-Vidales}

Profesora en la Universidad de Valladolid (España) y miembro del claustro de profesores de varios másteres oficiales y especializados. Es, además, directora del Observatorio del ocio y el entretenimiento digital, Ocendi, y colaboradora de varios medios de comunicación. Ha publicado varios artículos científicos y libros sobre radio y televisión, el último de ellos Radio 3. Una nueva radio para una nueva era (Fragua, 2011), de la que es editora y coautora.

\section{Ana Azurmendi-Adarraga}

Profesora de Derecho de la Comunicación en la Universidad de Navarra. Autora de los libros Derecho de la Comunicación (Bosch, 2011) y autora y editora de la Reforma de la Televisión Pública Española (Tirant lo Blanch, 2007) y de varios artículos y capítulos de libro sobre la redefinición de la televisión pública en Europa.

\section{Miguel Ángel Ortiz-Sobrino}

Profesor de Periodismo en la Universidad Complutense de Madrid. Es delegado de Medialabab/Inforadio y miembro de la Comisión de Calidad para el Grado de Periodismo en la Facultad de Ciencias de la Información de Madrid. Es autor de más de cincuenta contribuciones bibliográficas en revistas científicas. Entre otras contribuciones en 2011, ha editado y es coautor del libro Radio 3.0. Una nueva radio para una nueva era. 